\title{
Seismic Evaluation of Atypical Special Plate Shear Walls
}

\section{ASME Pressure Vessels and Piping Division Conference}

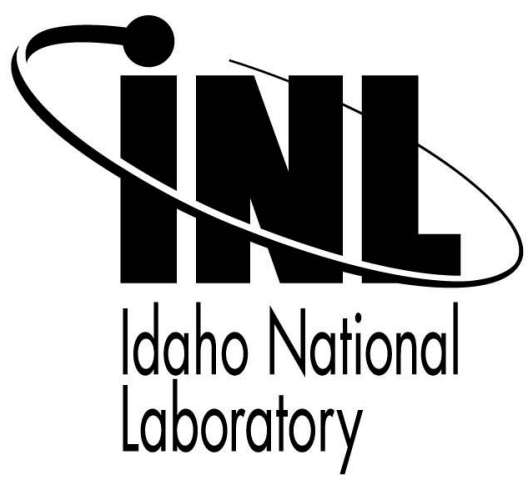

July 2007

This is a preprint of a paper intended for publication in a journal or proceedings. Since changes may be made before publication, this preprint should not be cited or reproduced without permission of the author. This document was prepared as an account of work sponsored by an agency of the United States Government. Neither the United States Government nor any agency thereof, or any of their employees, makes any warranty, expressed or implied, or assumes any legal liability or responsibility for any third party's use, or the results of such use, of any information, apparatus, product or process disclosed in this report, or represents that its use by such third party would not infringe privately owned rights. The views expressed in this paper are not necessarily those of the United States Government or the sponsoring agency. 


\title{
SEISMIC EVALUATION OF ATYPICAL SPECIAL PLATE SHEAR WALLS
}

\author{
M. J. Russell \\ Senior Structural Engineer \\ Idaho National Laboratory \\ Tel: 208-526-1608 \\ Fax: 208-526-4311 \\ E-Mail: Mark.Russell@inl.gov
}

\author{
R. E. Spears \\ Senior Research Engineer \\ Idaho National Laboratory \\ Tel: 208-526-4109 \\ Fax: 208-526-4311 \\ E-Mail: Robert.Spears@inl.gov
}

\author{
R. G. Kobbe \\ Structural Engineer \\ Idaho National Laboratory \\ Tel: 208-526-8862 \\ Fax: 208-526-4311 \\ E-Mail: Ryan.Kobbe@inl.gov
}

\begin{abstract}
The structure of a building undergoing a seismic reevaluation at the Idaho National Laboratory includes a number of steel plate walls and a roof liner which will act as shear diaphragms during an earthquake. Since the facility was designed and built long before such criteria were formulated, it is not surprising that these walls are not configured to meet all of the recently formulated requirements for such structures. To take advantage of these unusual structural elements, nonlinear analysis was used to ensure accurate modeling of the plate walls in a linear elastic seismic analysis of the full superstructure. The modeling was also used to establish the capacity of the plate.
\end{abstract}

\section{INTRODUCTION}

Seismic reevaluation of structures almost invariably involves earthquake loads that exceed the original design loads. This makes inadvertent but competent load paths found in the original design attractive elements in the reevaluation. Fire barrier ceiling and walls constructed of a grid of structural steel beams with welded steel plate facing are an example of such elements. These elements were found in a seismic reevaluation of an Idaho National Laboratory structure (See Figure 1). The tallest portion of the building covers a bay whose ceiling and East, South, and West walls are comprised of grids of steel beams welded to quarter inch thick steel plate. The structural evaluation of these walls is the subject of this paper.

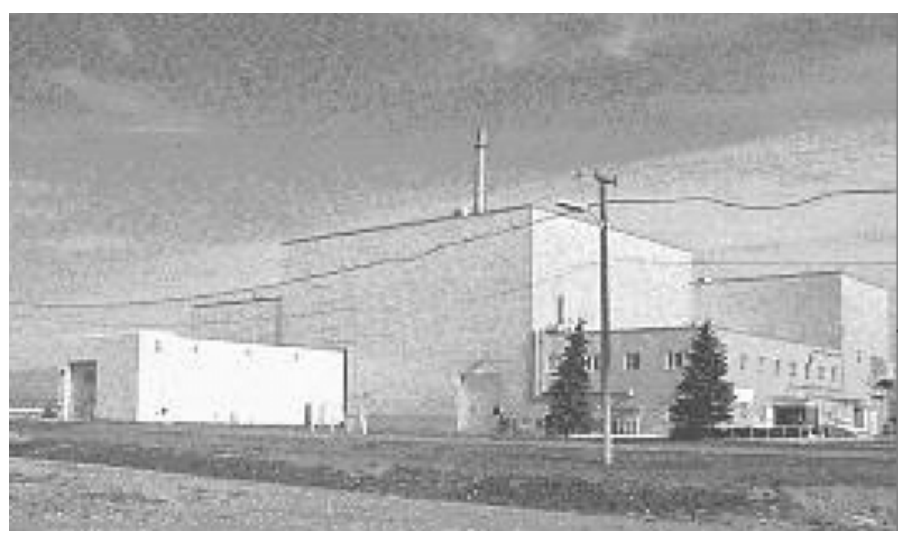

Figure 1. Structure under seismic reevaluation.

\section{PRELIMINARY STRUCTURAL EVALUATION}

Evaluation of the steel plate ceiling of the structure using the shear criteria from Section G2 of the AISC Steel Construction Manual, 13 ${ }^{\text {th }}$ Edition [1] established that the spacing of the grid of beams and stiffeners supporting the steel plate out-of-plane was tight enough that linear behavior could be expected of it. The support spacings for the walls were not as tight, and they did not meet the AISC shear spacing criteria. In fact, dramatic reductions in shear capacity were needed to 
ensure elastic action. Elastic action was ensured for shear demands up to $4.5 \%$ of the capacity based solely on shear yielding. This criterion predicted that elastic buckling of the walls would govern their failure response.

The walls were then checked against the criteria for Special Plate Shear Walls found in the American Institute of Steel Construction Seismic Provisions [2]. They did not meet these criteria either. Oddly enough, the main reason was that the steel plate was too thick. The shear wall criteria are formulated to ensure plastic action is confined to the steel plate, leaving the frame members elastic to ensure stability of the shear wall. This plate is so thick that plastic response under the predicted seismic loads was expected to be extremely localized, if it occurred at all.

The situation presented two problems. First, how can the softening of the steel shear walls associated with the nonlinear elastic buckling of the steel plate be accurately represented in a linear elastic analysis? Second, what criteria are needed to ensure that the structures perform acceptably despite the elastic buckling response? These questions are answered in the following sections.

\section{STEEL PLATE WALL MODELING}

The three walls with steel plate were represented in the elastic model of the superstructure with standard beam elements representing the beams and the steel plate modeled as thin shells with a reduced Young's modulus to account for buckling. Both linear and nonlinear analyses of each wall were used to establish the reduced Young's modulus. The analyses were complicated by the presence of holes in two of the walls. The three walls will be discussed in order of complexity, from simplest to most complex.

Finite element analyses of the simplest wall (the East wall), nonlinear in geometry and material were run to generate an accurate picture of its expected performance. The analyses were done in three dimensions to capture the global buckling phenomenon. Boundary conditions included out-of-plane restraint provided by the major beams of the attaching out-ofplane walls and roof, and a single in-plane restraint at the left end of the bottom collector beam, representing a diagonal brace installed at that location (See Figure 2).

An initial out-of-plane equivalent static seismic acceleration was applied consistent with the three dimensional nature of earthquake motion. This ensured proper buckling initiation. The restraints at the ceiling were then displaced inplane. Bounding results of the calculation are in Figure 3.

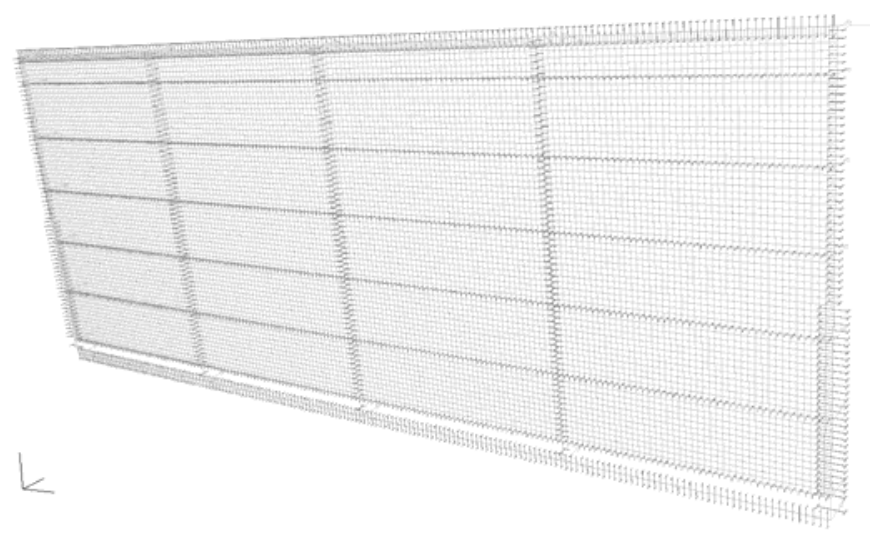

Figure 2. Nonlinear finite element model of the East wall.

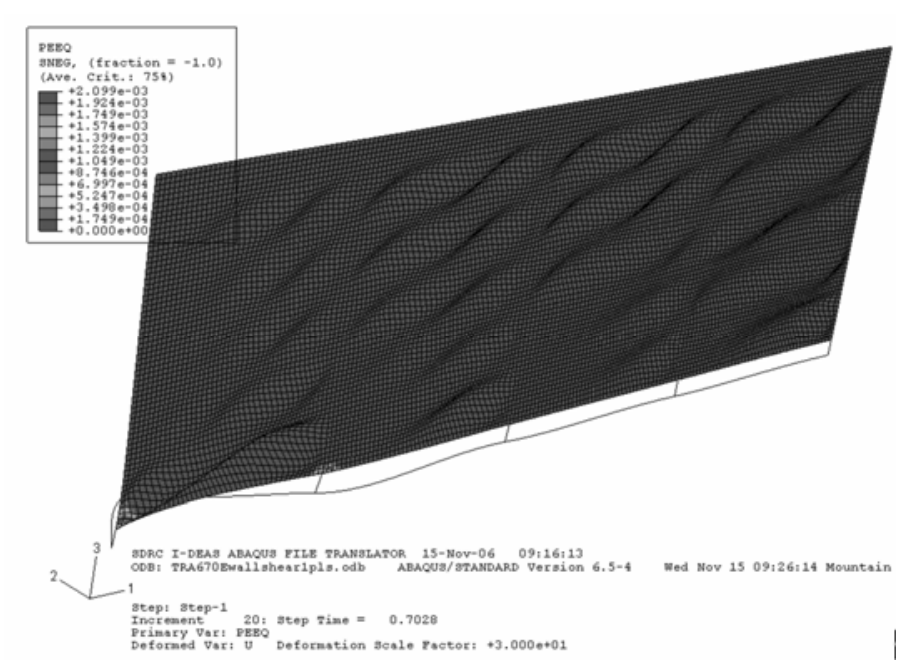

Figure 3. Bounding strain results from the nonlinear East Wall analysis.

The most striking feature of Figure 3 is the buckled pattern exhibited (Magnified X30 in the Figure). The pattern results from tension fields developing that run from lower left to upper right as the top of the frame is moved to the right. The fields have formed at an angle near 45 degrees. This is consistent with the deformation patterns for Special Plate Shear Walls described in the Commentary to the AISC 341-05 Seismic Provisions. The buckles are caused by local elastic deformation occurring orthogonal to the tension fields in response to the compression developing in that direction.

An elastic model, created by extracting the portion of the overall elastic model corresponding to the nonlinear model, is shown in Figure 4. The coarser grid is a consequence of the larger size of the full structural model. Boundary conditions were applied using the same logic, and the same loading scheme as was applied to the nonlinear model. 


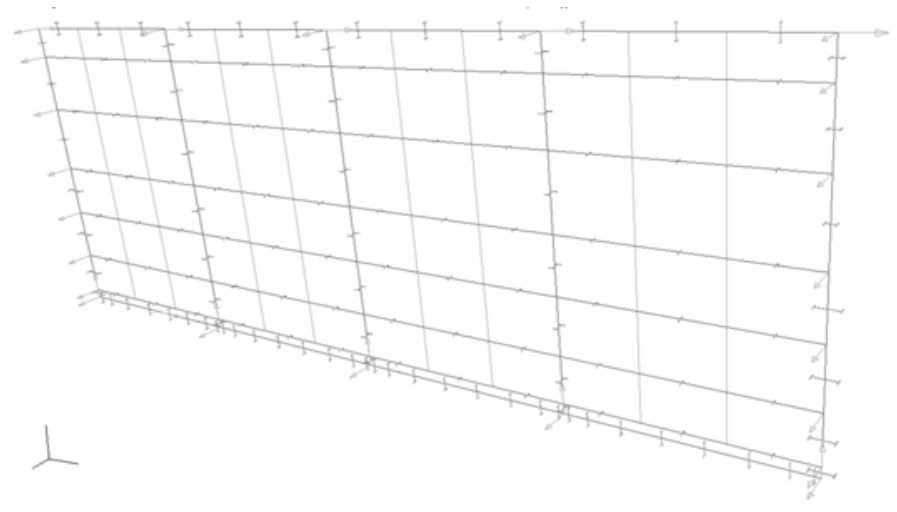

Figure 4. Elastic model of the East wall.

The elastic analysis was repeated for a number of different Young's moduli to provide data needed to correlate with that of the nonlinear model. This data allowed calculation of a Young's modulus to be used in the elastic seismic analysis of the entire structure that would yield a force-displacement behavior consistent with that of the nonlinear model. Figure 5 contains plots of the in-plane lateral displacement at the top of the wall versus the associated total shear force developed. The curved plot is the result of the nonlinear analysis. The straightline plots are results of the elastic analyses with various Young's moduli.

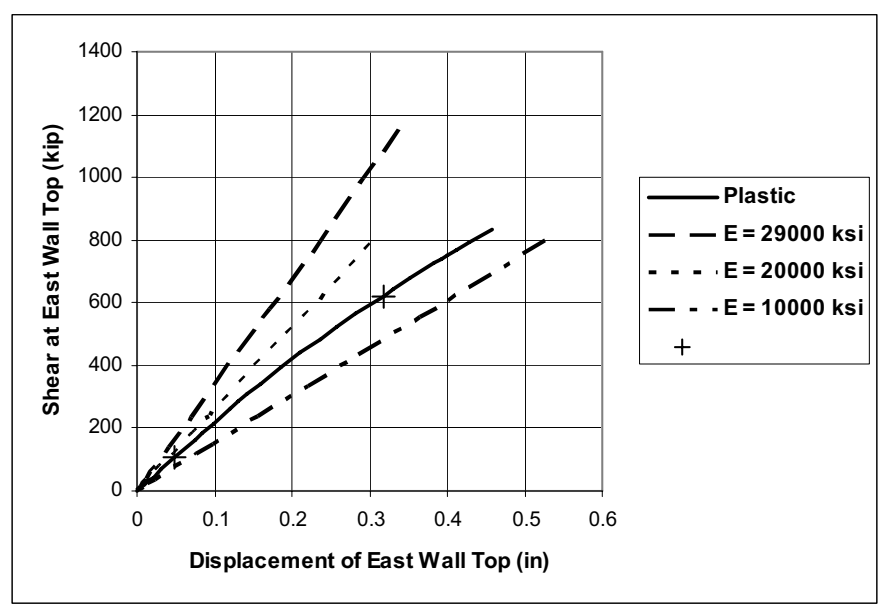

Figure 5. Plots of in-plane shear force versus displacement at the top of the East wall for the various models.

Calculation of the Young's modulus was done using a linear fit of Young's moduli as a function of slopes of the associated force displacement curves. For the data from Figure 5 above, the calculation would be:

$$
E_{p}=E_{10}+\frac{E_{20}-E_{10}}{k_{20}-k_{10}} \cdot\left(k_{p}-k_{10}\right)
$$

where:

$$
k_{i}=\frac{F_{i}}{X_{i}}
$$

and the variables are defined by:

$$
\begin{aligned}
& \mathrm{k}_{\mathrm{i}}=\text { Slope of the } \mathrm{i}_{\mathrm{th}} \text { curve of Figure } 5 . \\
& \mathrm{E}_{\mathrm{i}}=\text { Young's modulus associated with the } i_{\text {th }} \text { curve of } \\
& \text { Figure 5. For the nonlinear curve }(i=p) \text {, this is }
\end{aligned}
$$

The upper point on the plot $(+)$ is the force in the nonlinear model associated with the anticipated displacement of the wall in the superstructure analysis (the line for $i=p$ ). The Young's modulus associated with this point was used in the elastic analysis of the superstructure. The lower point is the force in the nonlinear model associated with the calculated displacement of the wall from the results of the superstructure analysis. Although the points are not close, the energies under the curves for the lines running from the origin through the two points differ by less than $10 \%$ at the displacement of the lower point. The Young's modulus used was considered acceptable. Another way of looking at this is to note that the slopes of the lines passing through the origin and the two points are nearly the same, so the associated Young's moduli will also be nearly the same.

Figure 5 shows the strain state at the in-plane displacement calculated for the East wall by the superstructure analysis (0.075-in). The zero plastic strain listed means that elastic response was calculated. This is in contrast to the strain at the maximum deformation calculated for the wall in the nonlinear analysis ( 0.457 -in) shown earlier in Figure 3 . Since the strains at maximum displacement show reasonably small maximum strains and regions of plastic strain, it has been taken as a lower bound on the capacity of the wall, and the ratio of displacements was taken as the Demand/Capacity ratio. 


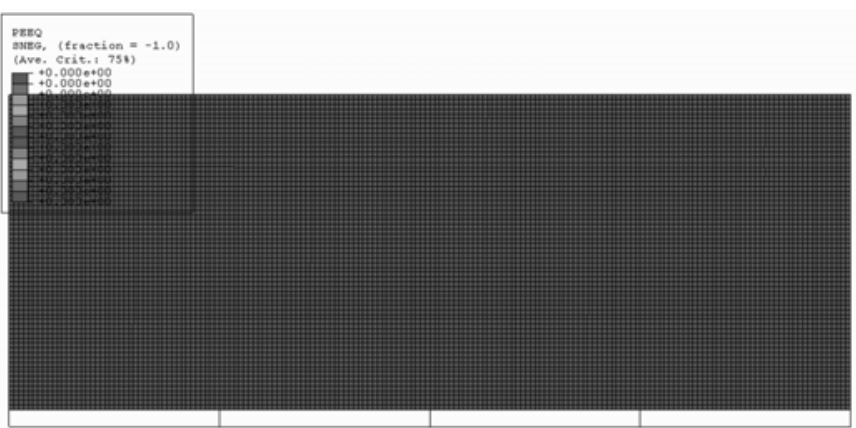

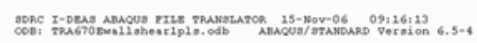

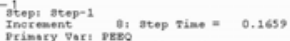

Figure 5. Plastic strains in the plate of the East wall at the maximum in-plane displacement predicted for the wall by the seismic analysis of the superstructure.

This same process was repeated for the South wall, but this wall has symmetrical openings (See Figure 6).

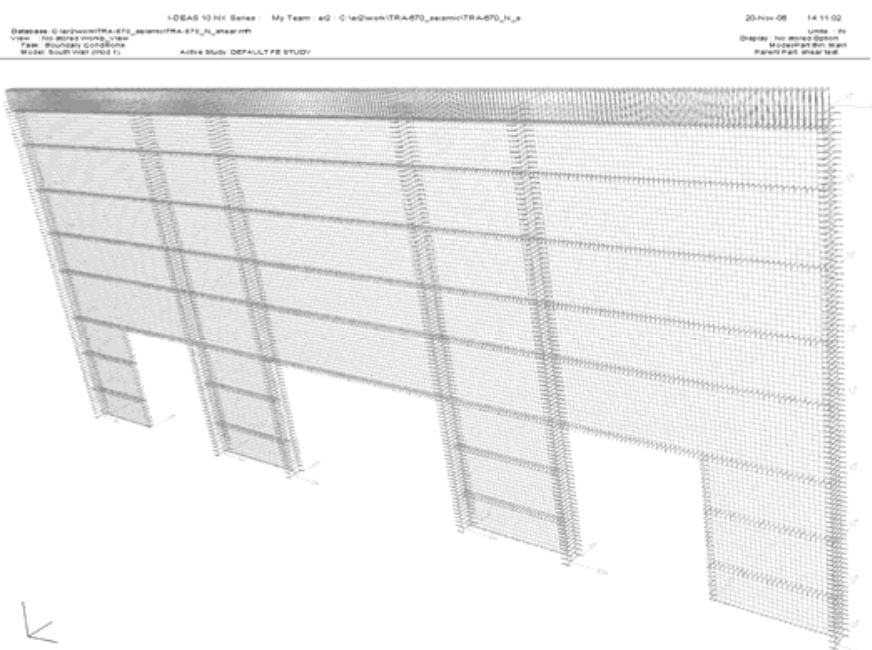

Figure 6. Nonlinear finite element model of the South wall.

Most of the flexibility of this wall occurs below the opening tops. A contour plot of in plane displacement (See Figure 7) shows that two thirds of the displacement occurs in the lower third of the wall where the openings are. Reduced Young's moduli were defined in the panels between openings to account for nonlinear wall softening, leaving the uncut upper panels' modulus unchanged.

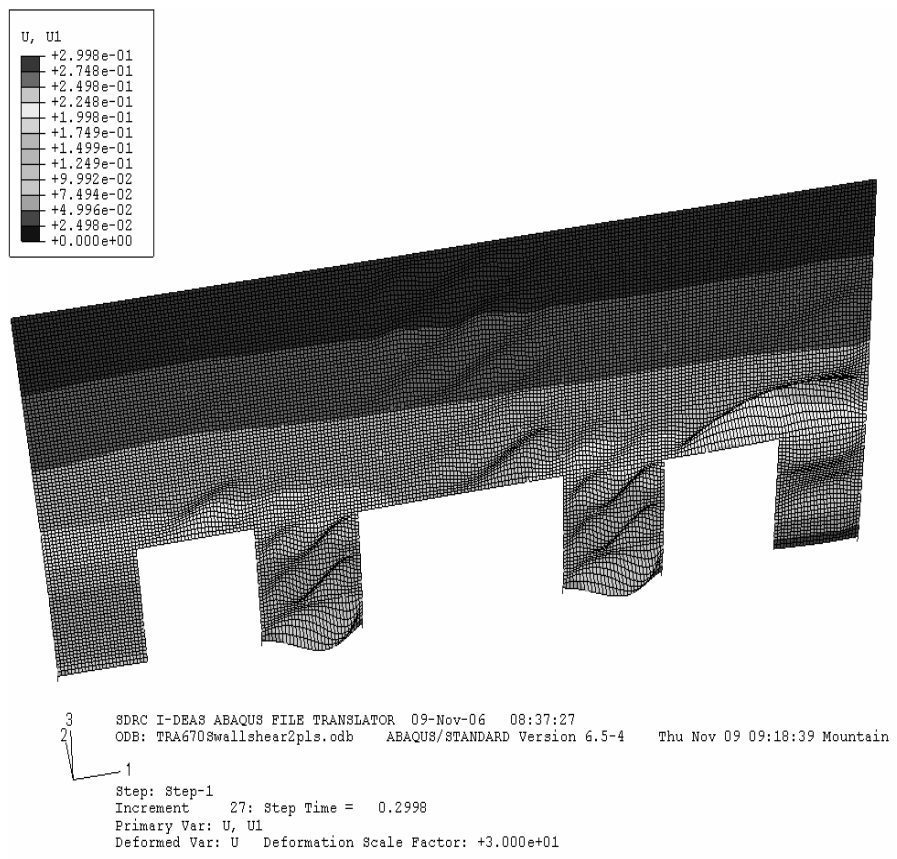

Figure 7. In-plane displacement of the South wall.

A careful second look at Figure 6 above establishes two types of panels left by the cutouts. The inner panels have a column (boundary element) on both sides, while the outer panels have a column on the exterior side and a nonstructural member on the interior side. Unlike symmetric panels, panels with non-symmetric boundary elements respond differently depending on the direction of load application. This can be explained by looking at the load path. Load has to be transmitted through both the plate and the boundary elements. Plate response reflects the fact that the magnitude of the tension force is controlled by the plate yield strength, while the magnitude of the compressive force is controlled by buckling capacity. Because buckling occurs well below yield, much larger tensile forces can occur. In a symmetric panel, the tension force is fully developed each half cycle. The fact that these forces develop in alternating locations has no effect on the composite response of the panel. It is symmetric. This is not the case with an asymmetric panel. Such panels have both stiff and flexible boundary elements. When the tension load path is through the stiff boundary element, the panel develops significantly larger shear force than when the tensile load path is through the flexible boundary element. The force displacement curves generated by a load applied on the South wall in the East direction show this effect (See Figure 8).

For the symmetric panels of the South wall, the plot for a reversed direction loading (to the West) would be identical, except that the "Left Outer" and "Right Outer" labels would be switched. This means that the composite response of the wall is the same regardless of the loading direction. An acceptable expression for Young's modulus for the outer panels can be obtained by calculating the individual moduli and applying 
their average to both outer panels of the linear superstructure model.

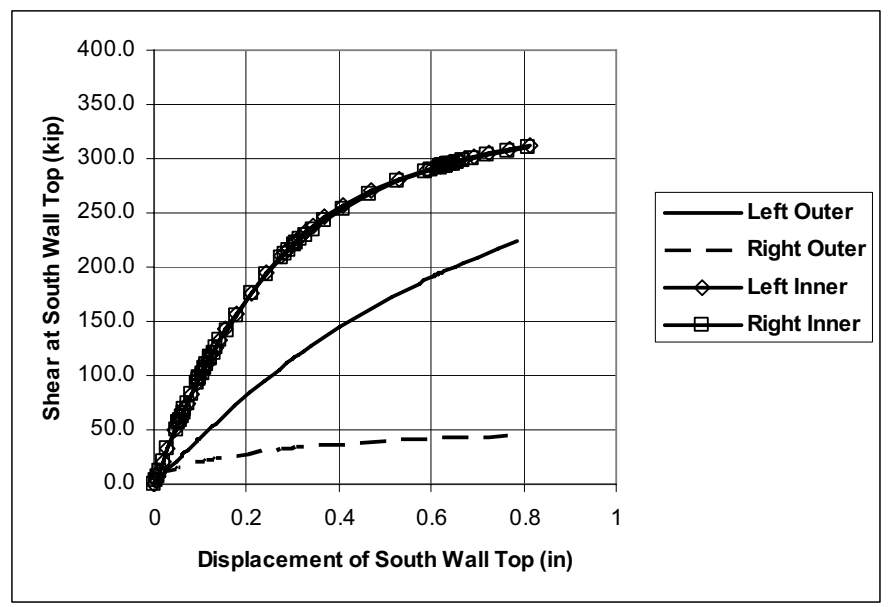

Figure 8. Plots of in-plane shear force versus displacement at the top of the South wall for the four bottom panels.

Use of an average modulus for the outer panels presents one problem. One of the two actual panels will experience a lower shear force than calculated by the elastic model. This is conservative. Unfortunately, the opposite panel will experience a higher load than calculated. This was addressed by increasing demands in the outer panel structures by an additive factor.

Figure 9 shows a plot of in-plane shear in the outer panels of the nonlinear South wall model (labeled "Strong Plastic" and "Weak Plastic") versus the shear in the same panels in the linear model (Labeled "Linear") Points are plotted for the shear/displacement values at the maximum displacement recorded in the linear analysis. The additive factor was obtained by subtracting the shear in the linear model from the shear in the more heavily loaded panel of the nonlinear model $(72-49=23)$. This factor was added to the forces of the beams subject to the loads generated in the panels. Moments associated with the forces were also increased proportionally.

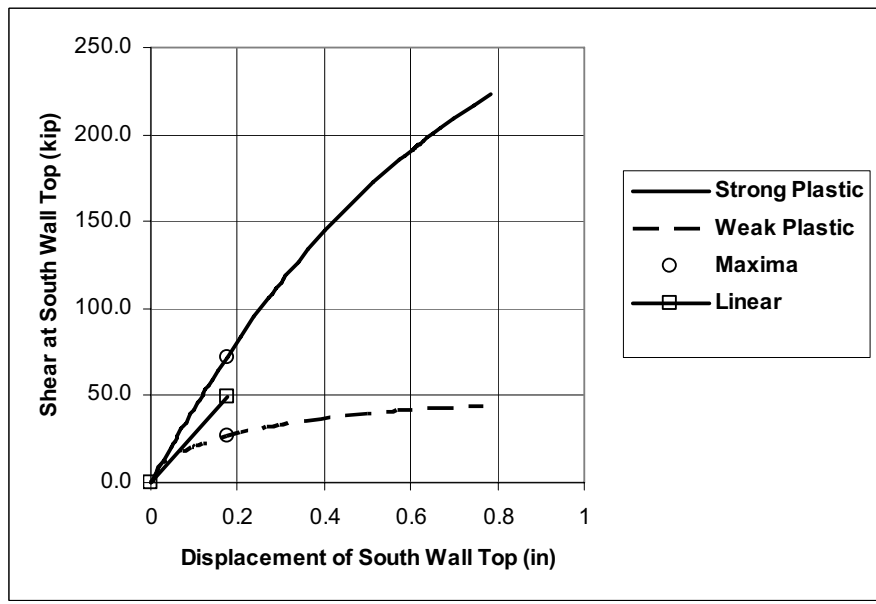

Figure 9. Plots of in-plane shear force in the outer panels and in the nonlinear and linear models versus displacement at the top of the South wall.

Figure 10 shows that plastic strains at the maximum displacement of the nonlinear analysis of the South wall model are small $(<0.2 \%)$ and localized. The welds attaching the plate to the surrounding beams are large enough that weld capacity exceeds that of the attached plate, so plate performance controls the performance of the welded plate structure. This is true of all the plate analyzed.

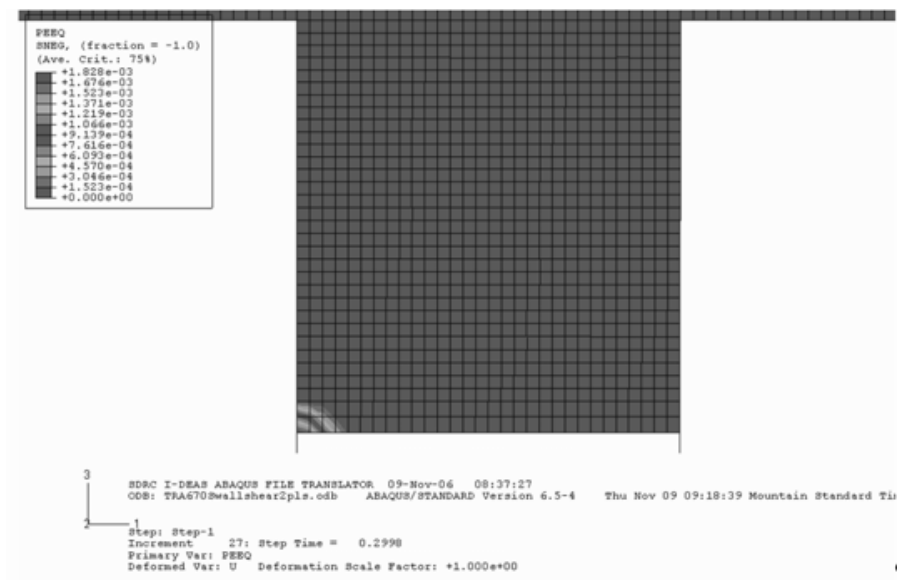

Figure 10. Plastic strains in the plate of the South wall at the maximum in-plane displacement predicted for the wall by the seismic analysis of the superstructure.

The evaluation of the North wall contained all the features of the two preceding walls, with one additional wrinkle. Figure 11 shows the nonlinear model of the wall and also shows its salient features. This wall is roughly the same as the South wall, with cutouts at the bottom that develop individual panels. The difference is that the panels don't occur in obvious symmetrical pairs. There are only three panels, and the middle panel has a hole cut in it for a personnel door. This means that the asymmetrical response to in-plane shear loads seen for individual panels of the South wall could also occur in the total response of the wall. 


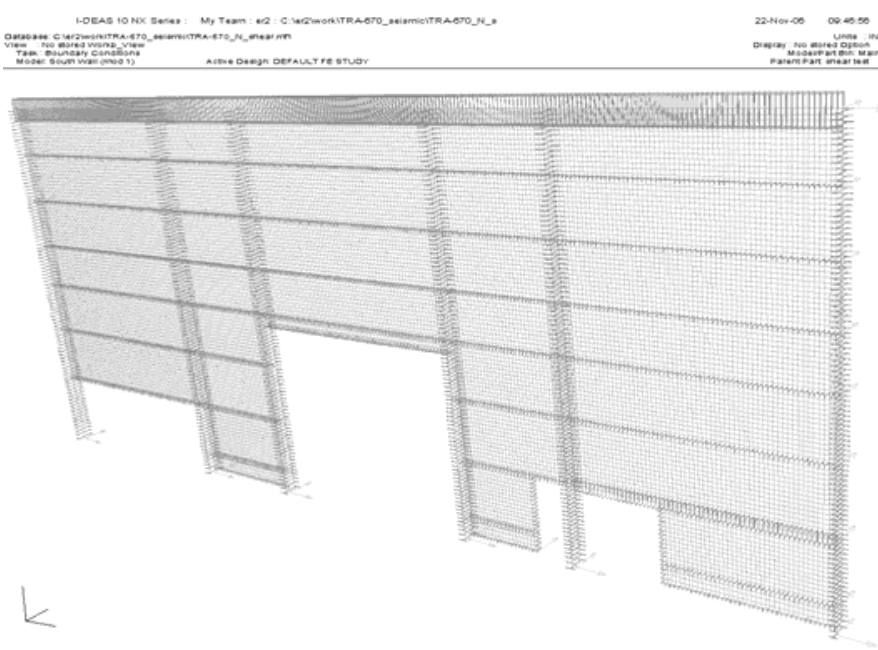

Figure 11. Nonlinear finite element model of the North wall.

Figure 12 shows a plot of total in-plane shear at the top of the North wall for both directions of loading. It shows that the differences in individual response cancel well in the summation, so that averaging the response of each individual panel would suffice for the total response also.

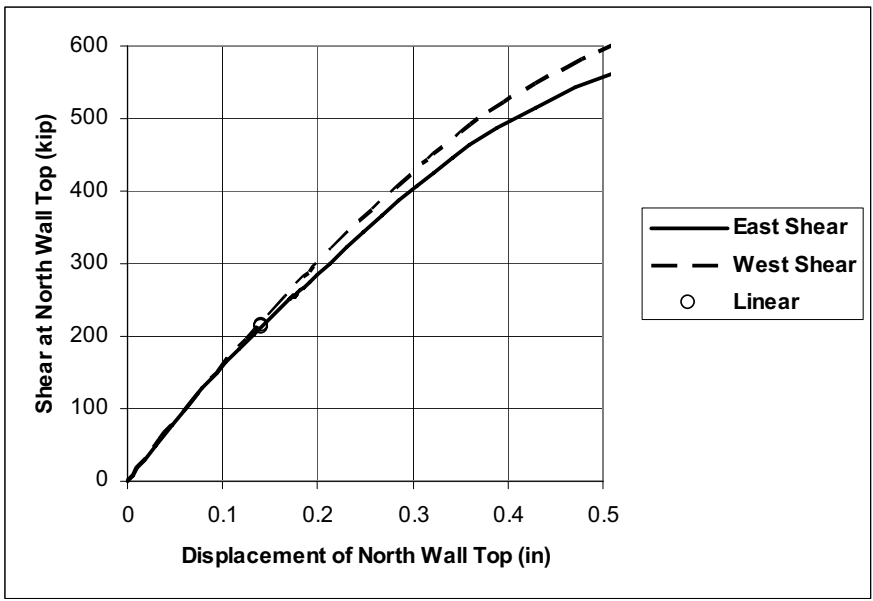

Figure 12. Plots of total in-plane shear force versus displacement at the top of the North wall.

Figure 13 shows that plastic strains at the maximum displacement of the nonlinear analysis of the South wall model are small $(<0.2 \%)$ and localized.
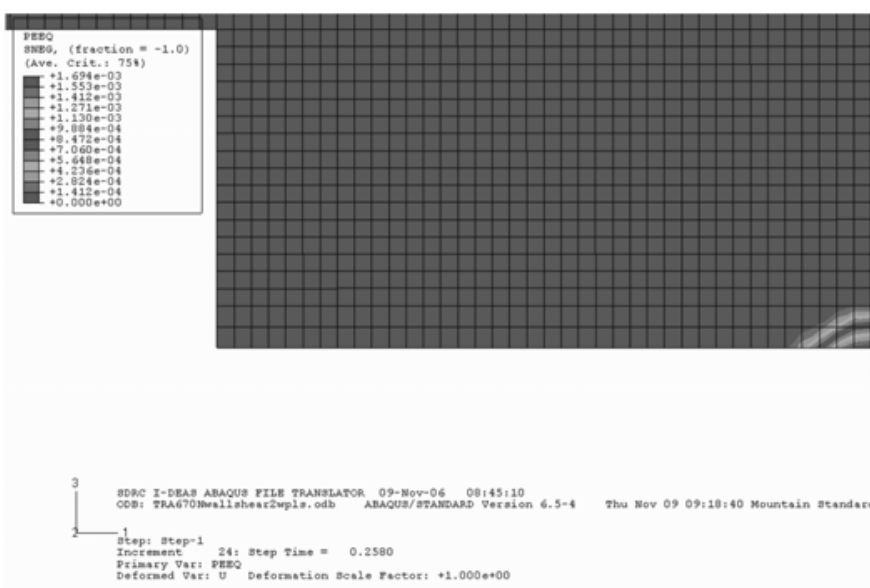

Figure 13. Plastic strains in the plate of the North wall at the maximum in-plane displacement predicted for the wall by the seismic analysis of the superstructure.

\section{STRUCTURAL CRITERIA}

The same nonlinear analyses that established the linear properties of the steel plate shear walls were also used to establish capacities for the steel plate used in their construction. Shear capacities of the welds attaching the plate to the steel framing and tensile capacity for the plate metal were determined per the AISC Specification. The capacity of the welds was shown to exceed that of the plate, justifying consideration of limited plate ductility. Ductility in the plate was characterized in the nonlinear analyses. Plate capacities were based on the maximum in-plane wall displacements achieved in the nonlinear analyses, with acceptability based on the low strains and small ranges of plastic deformation recorded for those limiting displacements. Demands were expressed in terms of the maximum in-plane wall displacements calculated in the elastic seismic analysis of the superstructure. Plastic strains in the wall plate associated with those displacements were low (on the order of a few tenths of a percent strain) and localized. Demand to Capacity $(\mathrm{D} / \mathrm{C})$ ratios ranged from 10 to $25 \%$.

\section{CONCLUSION}

Steel plate shears walls that don't meet current AISC requirements for linear elastic analysis may be qualified by inelastic analysis that characterizes an appropriate elastic representation of the walls in an elastic analysis, and provides capacities for evaluation of the elastic analysis results. Care must be taken when asymmetric response is predicted to ensure that the average results are amplified to account for the real structural response exceeding that average.

\section{ACKNOWLEDGEMENTS}

This manuscript has been authored by Battelle Energy Alliance, LLC under Contract No. DE-AC07-05ID14517 with the U.S. Department of Energy. The United States Government retains and the publisher, by accepting the article for publication, acknowledges that the United States Government 
retains a nonexclusive, paid-up, irrevocable, world-wide license to publish or reproduce the published form of this manuscript, or allow others to do so, for United States Government purposes.

\section{REFERENCES}

[1] ANSI/AISC 360-05, .Specification for Structural Steel Buildings, American Institute of Steel Construction, March 2005.

[2] ANSI/AISC 341-05, Seismic Provisions for Structural Steel Buildings Including Supplement No. 1, American Institute of Steel Construction, November, 2005. 